\title{
Changes in Carotid Intimal Medial Thickness (CIMT) With Glycaemic Control in Patients of T2DM
}

\author{
Dr. Sanjay Sud * \\ Visiting Consultant in Medicine, Konnagar Matri Sadan Municipal Hospital, Hooghly, \\ India Director of Doctor Sud's Clinic, Serampore, India \\ *Corresponding author: Dr. Sanjay Sud, Email: doctorsud70@gmail.com
}

Received 10 May 2019;

Accepted 21 June 2019;

Published 27 June 2019

\begin{abstract} CIMT - leading to a lowering of CVD risk

The inclusion criteria was

$>$ Non - pregnant Adults (Age $>18$ years)

$>\mathrm{T} 2 \mathrm{DM}$ with $\mathrm{HbA} 1 \mathrm{c} \geq 8 \%$ at recruitment

$>$ Those who remained normotensive (B.P. $\leq 130 / 80 \mathrm{~mm}$ of $\mathrm{Hg}$ )

$>$ Those who maintained a normal Lipid profile

$>$ Those who had eGFR $\geq 60 \mathrm{~mL} / \mathrm{min} / 1.73 \mathrm{~m}^{2}$ (CKD-EPI)

$>$ CIMT measurements done at recruitment and then once every year
\end{abstract}

A real world long term (10 years) prospective randomized observational study to monitor changes in CIMT of T2DM patients who achieved the target glycaemic goal of HbAlc $\leq 7 \%$, with those who did not achieve it. CIMT is a marker of subclinical atherosclerosis associated with CVD risk factors. Hence any progression or regression of CIMT could be considered as increased or decreased risk of CVD as the case might be. This study was to ascertain if (keeping all other risk factors under control and at par in each group) a good glycaemic control could lead to a lower

Exclusions

$>$ Any requirement for hospitalization throughout the entire 10 year duration

The total number of patients who completed the follow up for the full ten years was 62 .

CIMT of the CCAs were scanned with 7-10 MHz linear probe transducer under real time B mode imaging. The patients included in the study were divided into (Group A $n=32$ and Group B $n=30$ )

Group A were those who could achieve the glycaemic target of $\mathrm{HbAlc} \leq 7 \%$ by the end of the first year and were able to maintain the target for the major duration of the study.

Group B were those who did not achieve the glycaemic target of HbAlc $\leq 7 \%$ by the end of the first year of the study and had an average $\mathrm{HbAlc}$ of $\geq 7.5 \%$ for the major duration of the study

Results: The data at the end of ten year follow up showed that patients from

Group A had a mean CIMT of $0.79 \mathrm{~mm}$ at baseline and at the end of the study it was $0.75 \mathrm{~mm}$

Group B had a mean CIMT of $0.81 \mathrm{~mm}$ at baseline at baseline and at the end of study period was $1.17 \mathrm{~mm}$. $(\mathrm{p}<0.05)$

A good glycaemic control can reduce the burden of CVD as an independent entity.

Keywords: CIMT (Carotid Intimal Medial Thickness), CCAs (Common Carotid Arteries), CVD (Cardio Vascular Disease), T2DM (Type 2 Diabetes Mellitus), Glycaemic control

\section{Introduction}

A real world long term (10 years) prospective randomized observational study to monitor changes in CIMT of T2DM patients who achieved the target glycaemic goal of $\mathrm{HbAlc} \leq 7 \%$, with those who did not achieve the target. The targets of B.P. $\leq 130 / 80$ $\mathrm{mm}$ of $\mathrm{Hg}$, a normal Lipid profile and eGFR $\geq 60 \mathrm{~mL} / \mathrm{min} / 1.73 \mathrm{~m}^{2}$, with a comprehensive management for T2DM achieved by 
standard up-titration of anti-hyperglycaemic, anti-hypertensive medications and statins was common for both the groups of patients.

CIMT is a marker of subclinical atherosclerosis associated with conventional cardiovascular disease (CVD) risk factors. Using CIMT to predict CVD, a number of longitudinal studies have examined the relationship between CIMT and future events, most frequently the incidence of cardiac events (myocardial infarction, and angina pectoris) and cerebrovascular events (stroke or transient ischemic attacks). Hence any progression or regression of CIMT could be considered as increased or decreased risk of CVD as the case might be. This study was to ascertain if (keeping all other risk factors under control and at par in each group) a good glycaemic control could lead to a lower CIMT - leading to a lowering of CVD risk.

\section{Materials and methods}

The inclusion criteria for the study was

$>$ Non - pregnant Adults (Age $>18$ years)

$>\mathrm{T} 2 \mathrm{DM}$ with $\mathrm{HbAlc} \geq 8 \%$ at recruitment

$>$ Those who remained normotensive (B.P. $\leq 130 / 80 \mathrm{~mm}$ of $\mathrm{Hg}$ ) throughout the study

$>$ Those who maintained a normal Lipid profile (as per ADA criteria) throughout the study

$>$ Those who had eGFR $\geq 60 \mathrm{~mL} / \mathrm{min} / 1.73 \mathrm{~m}^{2}$ (CKD-EPI) throughout the study

$>$ CIMT measurements were done at recruitment and then once every year

\section{Exclusions}

$>$ Any requirement for hospitalization during the entire 10 year duration

All the above parameters were monitored at regular intervals (HbA1c every 3 months, B.P. every 3months, Lipids, CIMT and eGFR annually) throughout the entire duration of the study which was for 10 years (Feb 2010 - Jan 2019).

The number of patients who came back for regular follow-ups for complete 10 years was 62 .

Informed consent from all the patients was obtained and all the records were maintained in the digital database of the clinic. (The study was conducted by the author in his clinic - Doctor Sud's Clinic, having the facilities for Doppler and ultrasound imaging). CIMT was measured in all the cases by the author himself (So the chances of inter-observer variability was minimized).

CIMT of the Common Carotid Arteries (CCAs) were scanned using Sonosite Titan Ultrasound machine with 7-10 MHz linear probe transducer under real time B - mode imaging. After explanation of the procedure, the subjects were positioned supine with the desired neck extension achieved by pillow support under the neck. The neck was rotated $45^{\circ}$ away from the side being examined to give appropriate neck exposure to visualize the common carotid artery and the internal carotid artery. The air interface between the probe and the skin was minimized by the application of acoustic gel. The scan of the common carotid artery began just above the clavicle and the transducer was rotated cephalad through the bifurcation and parallel to the internal carotid artery. The presence of atherosclerotic plaque was scanned for in the near and far walls of the common carotid artery, the carotid bulb and the internal carotid artery to avoid measurement of the thickness at the site of plaque (if present) giving erroneously increased values. The intimal -media thickness of the far wall of the carotid vessels was measured as the distance between the leading edge of the lumen-intima interface and the leading edge of the media-adventitia interface. The mean of both sides (left and right) was recorded as the CIMT for that patient.

The patients included in the study were divided into two groups A (Table 1) and B (Table 2).

(Group A n $=32$ and Group B $n=30$ ). Total number $n=62$.

Patients in group A were those who could achieve the glycaemic target of $\mathrm{HbAlc} \leq 7 \%$ by the end of the first year and were able to maintain the target for the major duration of the study.

Patients in group B were those who did not achieve the glycaemic target of $\mathrm{HbAlc} \leq 7 \%$ by the end of the first year of the study and had an average $\mathrm{HbAlc}$ of $\geq 7.5 \%$ for the major duration of the study.

In both the above groups the other risk factors for co-morbidity like, hypertension, dyslipidaemia and microalbuminuria were kept under strict control as per the recommendations in the guidelines with titration of medications for their management. Hence ruling out any advantage / disadvantage modifying the progression / regression of CVD marker (CIMT). 


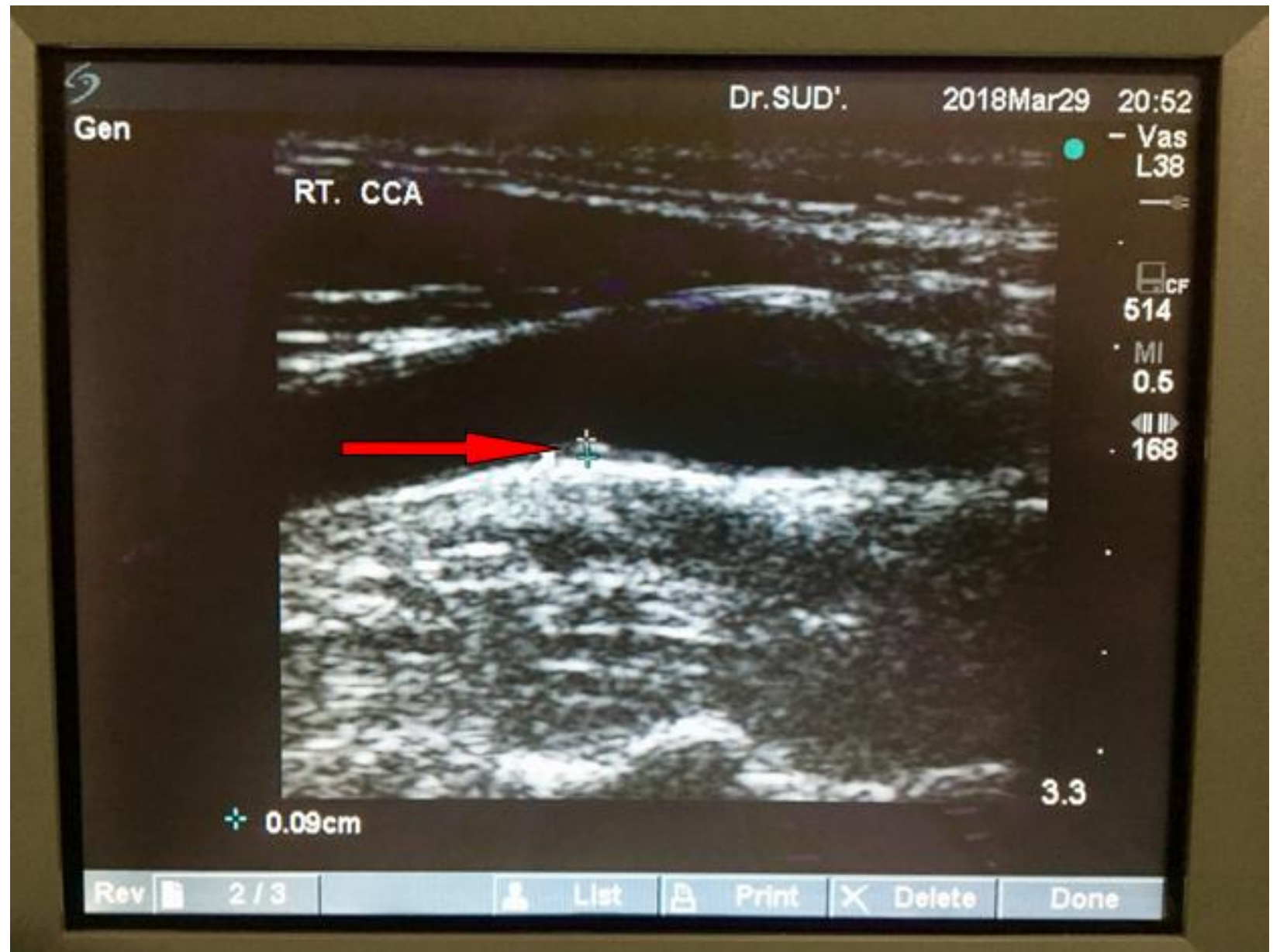

Figure 1: Measurement of carotid intimal medial thickness: The distance between the white + and blue + (marked with arrow), indicates the CIMT at the lower (distal) end of the Right Common Carotid Artery (CCA)

The annual CIMT values in mm for each patient in both the groups was serially recorded as shown in the tables below

Table 1: Group A

\begin{tabular}{|c|c|c|c|c|c|c|c|c|c|c|c|}
\hline \multirow[t]{3}{*}{ Pt. Serial No. } & \multicolumn{11}{|c|}{ CIMT in $\mathrm{mm}$} \\
\hline & YEAR & YEAR & YEAR & YEAR & YEAR & YEAR & YEAR & YEAR & YEAR & YEAR & YEAR \\
\hline & 2010 & 2011 & 2012 & 2012 & 2013 & 2014 & 2015 & 2016 & 2017 & 2018 & 2019 \\
\hline 1 & 0.7 & 0.8 & 0.7 & 0.7 & 0.8 & 0.7 & 0.7 & 0.7 & 0.7 & 0.8 & 0.7 \\
\hline 2 & 0.8 & 0.8 & 0.8 & 0.7 & 0.7 & 0.7 & 0.7 & 0.7 & 0.7 & 0.7 & 0.7 \\
\hline 3 & 0.6 & 0.7 & 0.7 & 0.7 & 0.6 & 0.7 & 0.7 & 0.7 & 0.6 & 0.6 & 0.6 \\
\hline 4 & 0.7 & 0.7 & 0.8 & 0.8 & 0.8 & 0.8 & 0.7 & 0.8 & 0.8 & 0.8 & 0.8 \\
\hline 5 & 0.8 & 0.7 & 0.7 & 0.7 & 0.7 & 0.6 & 0.6 & 0.6 & 0.6 & 0.6 & 0.6 \\
\hline 6 & 0.9 & 0.8 & 0.8 & 0.8 & 0.8 & 0.8 & 0.7 & 0.7 & 0.7 & 0.7 & 0.7 \\
\hline 7 & 0.8 & 0.8 & 0.7 & 0.7 & 0.7 & 0.7 & 0.7 & 0.7 & 0.7 & 0.7 & 0.7 \\
\hline 8 & 0.8 & 0.8 & 0.7 & 0.7 & 0.7 & 0.7 & 0.7 & 0.8 & 0.7 & 0.7 & 0.7 \\
\hline 9 & 0.9 & 0.8 & 0.8 & 0.8 & 0.8 & 0.7 & 0.7 & 0.7 & 0.7 & 0.7 & 0.7 \\
\hline 10 & 0.8 & 0.9 & 0.9 & 0.9 & 0.9 & 0.9 & 0.9 & 0.9 & 0.9 & 1.0 & 1.0 \\
\hline 11 & 0.8 & 0.9 & 0.9 & 0.8 & 0.8 & 0.8 & 0.7 & 0.7 & 0.7 & 0.7 & 0.7 \\
\hline 12 & 0.7 & 0.7 & 0.7 & 0.7 & 0.6 & 0.6 & 0.6 & 0.6 & 0.6 & 0.7 & 0.6 \\
\hline 13 & 0.7 & 0.7 & 0.7 & 0.8 & 0.8 & 0.7 & 0.7 & 0.7 & 0.7 & 0.7 & 0.7 \\
\hline 14 & 0.9 & 0.9 & 0.8 & 0.8 & 0.8 & 0.8 & 0.7 & 0.7 & 0.7 & 0.7 & 0.7 \\
\hline 15 & 0.8 & 0.8 & 0.7 & 0.7 & 0.7 & 0.7 & 0.7 & 0.7 & 0.7 & 0.7 & 0.7 \\
\hline 16 & 0.7 & 0.7 & 0.7 & 0.8 & 0.8 & 0.8 & 0.8 & 0.8 & 0.8 & 0.8 & 0.8 \\
\hline 17 & 0.9 & 0.9 & 0.8 & 0.8 & 0.8 & 0.8 & 0.8 & 0.8 & 0.8 & 0.9 & 0.9 \\
\hline 18 & 0.8 & 0.7 & 0.7 & 0.7 & 0.7 & 0.7 & 0.7 & 0.7 & 0.6 & 0.6 & 0.6 \\
\hline 19 & 0.8 & 0.8 & 0.8 & 0.7 & 0.7 & 0.7 & 0.7 & 0.7 & 0.7 & 0.7 & 0.7 \\
\hline 20 & 0.7 & 0.7 & 0.7 & 0.8 & 0.8 & 0.8 & 0.8 & 0.8 & 0.8 & 0.8 & 0.8 \\
\hline 21 & 0.9 & 0.8 & 0.8 & 0.8 & 0.8 & 0.8 & 0.7 & 0.7 & 0.7 & 0.7 & 0.7 \\
\hline 22 & 0.8 & 0.8 & 0.8 & 0.8 & 0.7 & 0.7 & 0.7 & 0.7 & 0.7 & 0.7 & 0.7 \\
\hline 23 & 0.8 & 0.8 & 0.9 & 0.9 & 0.9 & 0.8 & 0.8 & 0.8 & 0.8 & 0.8 & 0.8 \\
\hline
\end{tabular}




\begin{tabular}{|l|l|l|l|l|l|l|l|l|l|l|l|}
\hline 24 & 0.7 & 0.7 & 0.8 & 0.8 & 0.8 & 0.7 & 0.7 & 0.7 & 0.7 & 0.7 & 0.7 \\
\hline 25 & 0.8 & 0.7 & 0.7 & 0.7 & 0.7 & 0.7 & 0.7 & 0.7 & 0.7 & 0.7 & 0.7 \\
\hline 26 & 0.8 & 0.9 & 0.9 & 0.9 & 0.9 & 0.9 & 0.9 & 0.9 & 0.9 & 0.9 & 1.0 \\
\hline 27 & 0.9 & 0.9 & 0.9 & 1.0 & 1.0 & 1.0 & 0.9 & 0.9 & 0.9 & 0.9 & 1.0 \\
\hline 28 & 0.7 & 0.8 & 0.7 & 0.7 & 0.7 & 0.7 & 0.7 & 0.7 & 0.8 & 0.8 & 0.8 \\
\hline 29 & 1.0 & 1.0 & 1.0 & 1.0 & 1.0 & 1.0 & 1.2 & 1.2 & 1.2 & 1.2 & 1.2 \\
\hline 30 & 0.7 & 0.7 & 0.6 & 0.6 & 0.7 & 0.6 & 0.6 & 0.7 & 0.6 & 0.6 & 0.6 \\
\hline 31 & 0.8 & 0.8 & 0.8 & 0.9 & 0.9 & 0.8 & 0.8 & 0.8 & 0.8 & 0.8 & 0.8 \\
\hline 32 & 0.9 & 0.8 & 0.8 & 0.8 & 0.7 & 0.7 & 0.7 & 0.7 & 0.7 & 0.7 & 0.7 \\
\hline
\end{tabular}

Table 2: Group B

\begin{tabular}{|c|c|c|c|c|c|c|c|c|c|c|c|}
\hline \multirow[t]{3}{*}{ Pt. Serial No. } & \multicolumn{11}{|c|}{ CIMT in $\mathrm{mm}$} \\
\hline & YEAR & YEAR & YEAR & YEAR & YEAR & YEAR & YEAR & YEAR & YEAR & YEAR & YEAR \\
\hline & 2010 & 2011 & 2012 & 2012 & 2013 & 2014 & 2015 & 2016 & 2017 & 2018 & 2019 \\
\hline 1 & 0.8 & 0.8 & 0.8 & 0.8 & 0.8 & 0.9 & 0.9 & 1.0 & 1.0 & 1.2 & 1.2 \\
\hline 2 & 0.8 & 0.8 & 0.9 & 0.9 & 0.9 & 0.9 & 1.0 & 1.0 & 1.0 & 1.1 & 1.1 \\
\hline 3 & 0.9 & 0.9 & 1.0 & 1.0 & 1.0 & 1.0 & 1.1 & 1.1 & 1.2 & 1.2 & 1.2 \\
\hline 4 & 0.7 & 0.7 & 0.8 & 0.8 & 0.8 & 0.8 & 0.9 & 0.9 & 0.9 & 0.9 & 0.9 \\
\hline 5 & 0.8 & 0.8 & 0.8 & 0.9 & 0.9 & 0.9 & 0.9 & 1.0 & 1.0 & 1.0 & 1.0 \\
\hline 6 & 0.9 & 0.9 & 0.8 & 0.8 & 0.8 & 0.9 & 0.8 & 0.8 & 0.9 & 0.9 & 0.9 \\
\hline 7 & 0.8 & 0.8 & 0.9 & 0.9 & 0.8 & 0.8 & 0.7 & 0.7 & 0.8 & 0.8 & 0.8 \\
\hline 8 & 0.7 & 0.7 & 0.6 & 0.7 & 0.7 & 0.8 & 0.8 & 0.9 & 0.9 & 1.0 & 1.0 \\
\hline 9 & 0.9 & 0.8 & 0.8 & 0.8 & 0.9 & 0.9 & 0.9 & 1.0 & 1.0 & 1.1 & 1.2 \\
\hline 10 & 0.8 & 0.8 & 0.7 & 0.7 & 0.8 & 0.9 & 0.9 & 0.9 & 1.0 & 1.0 & 1.2 \\
\hline 11 & 0.9 & 0.9 & 0.9 & 1.0 & 1.0 & 1.1 & 1.2 & 1.1 & 1.2 & 1.2 & 1.3 \\
\hline 12 & 0.8 & 0.8 & 0.9 & 0.9 & 0.9 & 0.9 & 0.9 & 1.0 & 1.0 & 1.0 & 1.1 \\
\hline 13 & 0.7 & 0.7 & 0.8 & 0.8 & 0.8 & 0.9 & 0.9 & 0.9 & 1.0 & 1.0 & 1.0 \\
\hline 14 & 0.7 & 0.7 & 0.7 & 0.8 & 0.8 & 0.9 & 0.9 & 0.9 & 1.0 & 1.0 & 1.0 \\
\hline 15 & 0.8 & 0.8 & 0.7 & 0.8 & 0.8 & 0.9 & 0.9 & 1.0 & 1.0 & 1.1 & 1.1 \\
\hline 16 & 0.9 & 0.9 & 0.9 & 1.0 & 1.0 & 1.1 & 1.2 & 1.2 & 1.2 & 1.3 & 1.3 \\
\hline 17 & 0.9 & 0.8 & 0.9 & 0.9 & 0.9 & 1.0 & 1.0 & 1.1 & 1.2 & 1.2 & 1.3 \\
\hline 18 & 0.8 & 0.8 & 0.9 & 0.9 & 1.0 & 1.0 & 1.2 & 1.2 & 1.2 & 1.2 & 1.2 \\
\hline 19 & 0.8 & 0.8 & 0.8 & 0.9 & 0.9 & 1.0 & 1.0 & 1.0 & 1.2 & 1.2 & 1.2 \\
\hline 20 & 0.9 & 0.9 & 0.8 & 1.0 & 1.0 & 1.0 & 1.1 & 1.2 & 1.2 & 1.3 & 1.3 \\
\hline 21 & 0.9 & 0.9 & 0.8 & 0.9 & 0.9 & 1.0 & 1.0 & 1.1 & 1.1 & 1.2 & 1.2 \\
\hline 22 & 0.7 & 0.7 & 0.8 & 0.9 & 1.0 & 1.0 & 1.1 & 1.2 & 1.3 & 1.3 & 1.4 \\
\hline 23 & 0.8 & 0.7 & 0.8 & 0.9 & 0.9 & 0.9 & 1.0 & 1.0 & 1.1 & 1.2 & 1.2 \\
\hline 24 & 0.8 & 0.8 & 0.9 & 0.9 & 1.0 & 1.0 & 1.2 & 1.2 & 1.3 & 1.3 & 1.3 \\
\hline 25 & 0.9 & 0.8 & 0.9 & 0.9 & 1.0 & 1.0 & 1.1 & 1.1 & 1.2 & 1.2 & 1.3 \\
\hline 26 & 0.6 & 0.7 & 0.6 & 0.7 & 0.8 & 0.8 & 0.9 & 0.9 & 1.0 & 1.0 & 1.0 \\
\hline 27 & 0.7 & 0.7 & $\begin{array}{l}0.8 \\
\end{array}$ & 0.8 & 0.9 & 0.9 & 1.0 & 1.0 & 1.1 & 1.1 & 1.2 \\
\hline 28 & 0.8 & 0.8 & 0.9 & 0.9 & 1.0 & 1.0 & 1.0 & 1.1 & 1.2 & 1.2 & 1.3 \\
\hline 29 & 0.8 & 0.9 & 0.9 & 1.0 & 1.0 & 1.1 & 1.2 & 1.2 & 1.3 & 1.3 & 1.4 \\
\hline 30 & 0.9 & 0.8 & 0.9 & 0.9 & 1.0 & 1.0 & 1.1 & 1.2 & 1.2 & 1.3 & 1.4 \\
\hline
\end{tabular}

\section{Comments and Discussion:}

The data from both the groups was analyzed at the end of ten year follow up.

The patients in Group A had a mean CIMT of $0.79 \mathrm{~mm}$ at baseline and at the end of the study it was $0.75 \mathrm{~mm}$.

The patients in Group B had a mean CIMT of $0.81 \mathrm{~mm}$ at baseline and at the end of the study period was $1.17 \mathrm{~mm}$.

The results were statistically significant $(\mathrm{p}<0.05)$

\section{Conclusion}

So it can be concluded from the ten year prospective observational follow up that a good glycaemic control helps to reduce the CIMT in patients of T2DM over and above a good control of other risk factors like lipid and hypertension as an independent entity, and so can help to reduce the burden of CVD / macrovasular disease progression in these patients.

\section{Conflicts of interest}

None

\section{Funding Statement}

All the funding required for the study was done by the author himself using the infrastructure of Doctor Sud's Clinic

\section{Acknowledgments}

The author acknowledges active help and logistic support provided by the staff of Doctor Sud's Clinic and his wife, Mrs. Bhawana Sud 
for typing of the manuscript and full social and moral support throughout the study period, without which it would not be possible to complete the task.

\section{References}

[1] Einarson T, Hunchuck J, Hemels M (2010) Relationship between blood glucose and carotid intimal media thickness: A meta-analysis. Cardiovascular Diabetology 9: 37 .

[2] ÓLeary DH, Polak JF (2002) Intimal-Media Thickness: A Tool for Atherosclerosis Imaging and Event Prediction. Am J Cardiol 90 (suppl): 18L-21L.

[3] Lorenz MW, Markus HS, Bots ML, Rosvall M, Sitzer M (2007) Prediction of Clinical Cardiovascular Events With Carotid Intima-Media Thickness. A Systematic Review and Meta-Analysis. Circulation 115: 459-467.

[4] Polak JF, Pencina MJ, Pencina KM, ÓDonnell CJ, Wolf PA, et al. (2011) Carotid-Wall Intima-Media Thickness and Cardiovascular Events. N Engl J Med 365: 213-221.
[5] Faeh D, William J, Yerly P, Paccaud F, Bovet P (2007) Diabetes and pre-diabetes are associated with cardiovascular risk factors and carotid/femoral intimalmedia thickness independently of markers of insulin resistance and adiposity. Cardiovascular Diabetology 6: 32.

[6] Choi SW, Shin MH, Yun WJ, Kim HY, Lee YH, et al. (2011) Association between hemoglobin A1c, carotid atherosclerosis, arterial stiffness, and peripheral arterial disease in Korean type 2 diabetic patients. J Diab Complications 25: 7-13.

[7] Fitch KV, Stavrou E, Looby SE, Hemphill L, Jaff MR, et al. (2011) Association of cardiovascular risk factors with two surrogate markers of subclinical atherosclerosis: Endothelial function and carotid intimal media thickness. Atherosclerosis 217: 437-440.

[8] Bots ML, Mulder PG, Hofman A, van Es GA, Grobbee DE (1994) Reproducibility of carotid vessel wall thickness measurements. The Rotterdam Study. J Clinical Epidemiology 47: 921-930. 